\title{
Categorising ultra-processed foods in large-scale cohort studies: evidence from the Nurses' Health Studies, the Health Professionals Follow-up Study, and the Growing Up Today Study
}

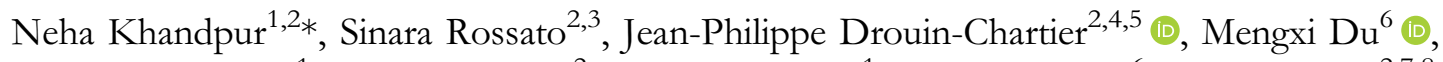
Euridice M. Steele $^{1}$, Laura Sampson ${ }^{2}$, Carlos Monteiro ${ }^{1}$, Fang F. Zhang ${ }^{6}$, Walter Willett ${ }^{2,7,8}$, Teresa T. Fung 2,9 (1) and Qi Sun ${ }^{2,7,8}$

${ }^{1}$ Department of Nutrition, School of Public Health, University of São Paulo, Av. Dr. Arnaldo, 715, São Paulo, Brazil

${ }^{2}$ Department of Nutrition, Harvard T.H. Chan School of Public Health, Boston, MA, USA

${ }^{3}$ Department of Public Health, Federal University of Uberlandia, Uberlandia, Minas Gerais, Brazil

${ }^{4}$ Center for Nutrition, Health and Society (NUTRISS), Institute for Nutrition and Functional Foods (INAF), Laval University, Quebec, QC, Canada

${ }^{5}$ Faculty of Pharmacy, Laval University, Quebec, QC, Canada

${ }^{6}$ Department of Public Health \& Community Medicine, Friedman School of Nutrition, Tufts University, Medford, MA, USA

${ }^{7}$ Department of Epidemiology, Harvard T.H. Chan School of Public Health, Boston, MA, USA

${ }^{8}$ Channing Division of Network. Medicine, Department of Medicine, Brigham and Women's Hospital and Harvard Medical School, Boston, MA, USA

${ }^{9}$ Department of Nutrition, Simmons University, Boston, MA, USA

(Received 3 June 2021 - Final revision received 13 August 2021 - Accepted 19 August 2021)

Journal of Nutritional Science (2021), vol. 10, e77, page 1 of 15

doi:10.1017/jns.2021.72

\section{Abstract}

This manuscript details the strategy employed for categorising food items based on their processing levels into the four NOVA groups. Semi-quantitative food frequency questionnaires (FFQs) from the Nurses' Health Studies (NHS) I and II, the Health Professionals Follow-up Study (HPFS) and the Growing Up Today Studies (GUTS) I and II cohorts were used. The four-stage approach included: (i) the creation of a complete food list from the FFQs; (ii) assignment of food items to a NOVA group by three researchers; (iii) checking for consensus in categorisation and shortlisting discordant food items; (iv) discussions with experts and use of additional resources (research dieticians, cohort-specific documents, online grocery store scans) to guide the final categorisation of the short-listed items. At stage 1, 205 and 315 food items were compiled from the NHS and HPFS, and the GUTS FFQs, respectively. Over $70 \%$ of food items from all cohorts were assigned to a NOVA group after stage 2. The remainder were shortlisted for further discussion (stage 3). After two rounds of reviews at stage 4, 95.6\% of food items (NHS + HPFS) and 90.7 \% items (GUTS) were categorised. The remaining products were assigned to a non-ultra-processed food group (primary categorisation) and flagged for sensitivity analyses at which point they would be categorised as ultra-processed. Of all items in the food lists, $36.1 \%$ in the NHS and HPFS cohorts and $43.5 \%$ in the GUTS cohorts were identified as ultra-processed. Future work is needed to validate this approach. Documentation and discussions of alternative approaches for categorisation are encouraged.

Key words: Cohort studies: Diet categorisation: Expert discussion: Food frequency questionnaires: Nova groups: Ultra-processed foods

Abbreviations: FFQ: food frequency questionnaire; GUTS: Growing Up Today Study; NHS: Nurses’ Health Study

* Corresponding author: Neha Khandpur, email neha12@mail.harvard.edu

(C) The Author(s), 2021. Published by Cambridge University Press on behalf of The Nutrition Society. This is an Open Access article, distributed under the terms of the Creative Commons Attribution licence (http://creativecommons.org/licenses/by/4.0/), which permits unrestricted re-use, distribution, and reproduction in any medium, provided the original work is properly cited. 


\section{Introduction}

Ultra-processed foods are ready-to-eat/heat industrial formulations of food substances that have been derived from whole foods, and that typically contain added flavours, colours and other cosmetic additives ${ }^{(1)}$. They are one of the four groups that make up the NOVA classification - a system that classifies food based on the extent and purpose of the industrial processing they undergo and accounts for the physical, biological and chemical methods used in their manufacture, including the use of additives ${ }^{(1)}$. Recently, observational studies have provided the first evidence for the health harms associated with the intake of ultra-processed foods ${ }^{(2-4)}$.

For the most part, the large-scale prospective cohort studies that have assessed the associations between ultra-processed foods and disease outcomes have used a self-administered food frequency questionnaire (FFQ) for repeated dietary assessment ${ }^{(5-9)}$. However, the food lists on the basis of which dietary information is collected are designed to have a limited number of pre-defined items which represent the primary sources of energy and nutrients in the population under study ${ }^{(10)}$. As such, FFQs are unable to cover the full spectrum of foods consumed, including ultra-processed foods. Additionally, all supporting information that would be useful in identifying the ultra-processed products from the food lists like cooking methods used, food combinations and ingredients, place of food consumption and brand names of packaged products are usually not captured by FFQs.

Capturing ultra-processed food intake may not have been the explicit goal of epidemiologic studies at the time of their inception. This would have implications for the development of their dietary assessment instruments. Even 24-h diet recalls or diet records that describe with some detail the foods eaten and their method of preparation, may therefore still lack the granularity needed to accurately identify all ultra-processed products. This may result in some ambiguity in the identification of the grade of processing of a subset of food items from different dietary assessment methods and not limited to FFQs, creating an opportunity for discussion of the possible approaches for improving the identification and estimation of ultra-processed foods in epidemiologic studies.

There is limited documentation of the approaches used in the classification of food intake into the four NOVA categories or in the identification of ultra-processed foods. To our knowledge, no previous study has explicitly presented the process used in the identification of ultra-processed foods from FFQs in sufficient detail to aid replication. As a result, the challenges encountered in the process of manual classification of the diet, or the decisions made to address them have not been systematically documented. Potential sources of misclassification may also be overlooked. This gap in the evidence base hinders progress in streamlining the application of the NOVA classification to dietary intake, in identifying ultra-processed foods, in estimating their contribution to the diet, and in improving dietary assessment methods to better capture food processing levels.

The purpose of this manuscript is to detail the approach for categorising food items captured by semi-quantitative FFQs of the Nurses' Health Studies I and II, the Health Professionals
Follow-up Study (HPFS) and the Growing Up Today Study I and II, into the four NOVA groups and to identify ultraprocessed foods. Collectively, these cohorts have made important contributions to the evidence base informing dietary guidelines and nutrition policy ${ }^{(11)}$ and their semi-quantitative FFQs have served as a template for FFQs used in epidemiologic studies, globally ${ }^{(12-14)}$. Presenting the strategy adopted in these cohorts will inform the categorisation of the diet in other studies that use similar assessment methods. While no validation work is presented, the broader goal of this manuscript is to encourage discussions on approaches to categorise dietary data into the NOVA groups and to inform the evolution of dietary assessment methods.

\section{Methods}

\section{Cohort details}

The first cohort of the Nurses' Health Study (NHS) in 1976 enrolled 121701 female registered nurses, aged 30 and 55 years $^{(15)}$. In 1986, 51529 male health professionals, aged 40 and 75 years, comprised the first cohort of the $\operatorname{HPFS}^{(16)}$, and in 1989, the first cohort of the NHS-II began with 116 686 female registered nurses, aged 25-42 years. Since then, participants in all three adult cohorts complete a biennial follow-up questionnaire on their medical history, lifestyle factors and occurrence of chronic diseases.

In 1996, the children of the NHS-II study participants were recruited into a study of their own - the Growing Up Today Study (GUTS) ${ }^{(17)}$. At inception, GUTS included 16882 girls and boys aged between 9 and 14 years. In 2004, the study expanded to include a second cohort of 10920 children between the ages of 10 and 17 years - the GUTS-II cohort. The two youth cohorts were followed biannually until 2013 when they were merged into one cohort.

\section{Assessment of food intake}

Dietary data from all waves of both the adult and the youth cohorts were collected using a self-administered, semiquantitative $\mathrm{FFQ}^{(15,17)}$. The first FFQ used in 1984 had 116 items and information on the usual intake of food and beverages from the NHS participants. This FFQ was expanded in 1986 to $\sim 130$ foods and sent every 4 years to track the diets of participants in both the NHS and the HPFS cohorts (NHS-II, since 1991). The GUTS FFQ included $\sim 150$ food items and was modified from the validated adult FFQ to the cognitive level and dietary knowledge of adolescents. It specifically included snack foods consumed by a younger population and food eaten away from home ${ }^{(17)}$. The FFQs continue to be updated to capture more detailed information on cooking methods and relevant food items ${ }^{(15)}$.

All FFQs ask participants how often, on average, they consumed a given reference portion of a food item over the course of the previous year. A total of nine response categories capture usual intake, ranging from 'never or less than once/ month' to ' $\geq 6$ times/day.' The reproducibility and validity of these FFQs have been extensively evaluated ${ }^{(16-19)}$. Nutrient intakes are estimated on the basis of a daily weight assigned to each food item based on its frequency of consumption ${ }^{(19)}$. 
A database of the nutrient content of FFQ food items maintained by study dietitians, the Harvard nutrient database, began in $1984^{(15)}$. It has been updated every 4 years to reflect changes to nutrient composition (e.g., changes in trans fat content). It also includes new food items and the most recent information on food components based on the U.S. Department of Agriculture (USDA) Nutrient Database for Standard Reference and the Food and Nutrients Database for Dietary Studies.

\section{Classification of food items into the NOVA groups}

The NOVA classification considers the extent and purpose of processing of the food item and includes four groups - (1) unprocessed or minimally processed food, (2) processed culinary ingredients, (3) processed foods and (4) ultra-processed foods. The first three NOVA groups include food products that have undergone processing methods like grinding, roasting, pasteurisation, freezing, vacuum packaging or nonalcoholic fermentation (minimally processed foods), centrifuging, refining or extracting (processed culinary ingredients) or preservation methods such as canning and bottling (processed foods) ${ }^{(1)}$. The category of ultra-processed foods includes food items that normally undergo more intensive industrial processing like hydrolysis, or hydrogenation, extrusion, moulding and pre-frying.

A four-stage process was undertaken to identify the ultraprocessed foods from both the adult and the youth FFQs. First, all food items in the FFQs across different waves of data collection were complied. Food items that were nearly identical between FFQs but were presented with minor differences were captured as separate items (e.g., 'Cold breakfast cereal ( 1 bowl)' and 'Cold breakfast cereal (1 serving)'). This was done to make sure that no food item was overlooked. FFQs from every 4 years of the NHS-I (1986-2010), the NHS-II (1991-2015), the HPFS (1986-2014), from 1996, 1998, 2001 for GUTS-I and from 2004, 2006, 2008, 2011 for GUTS-II were used.

Second, three researchers working independently assigned foods in the adult (N.K, S.R, E.M) and the youth (N.K, M.D, E.M) cohorts to one of the four NOVA groups based on their grade of processing - unprocessed/minimally processed foods (G1), processed culinary ingredients (G2), processed foods (G3) and ultra-processed foods (G4). Food assignment was guided by the definition, examples and supplementary material published by the proponents of the NOVA classification ${ }^{(1)}$. Categorisation was an iterative process requiring the review of the original FFQs used at each wave of data collection to contextualise food items within the larger food lists. Food preparations made from multiple ingredients or different food items that were presented jointly in the FFQ were not disaggregated into their different components. Additionally, the nutrient profile of food items, their actual amounts consumed by the study participants or participant demographics were not considered at any point in the categorisation process. Instead, the original food item as it was listed in the FFQ was categorised in its entirety.

At the third stage, categorisation between researchers was triangulated. Food items for which there was consensus in the categorisation among all researchers were assigned to their NOVA group. A food item was flagged for further scrutiny and shortlisted in case a researcher was unable to assign it to a NOVA group or in cases of disagreement in categorisation by any two researchers.

At stage four, an expert panel comprising of three senior nutrition epidemiologists (F.F.Z; T.F; Q.S) with substantial experience working with the dietary intake in these cohorts, was convened to review and discuss the categorisation of the short-listed products. All discussions were additionally informed by the following resources:

(1) Consultations with the research dietitians. The team of research dietitians, led by L.S, was responsible for overseeing the collection of dietary data and for ascertaining the nutrient composition of food items across all Harvard cohorts. They shared their insights obtained from gathering supplementary data, tracking new and reformulated products available in the supermarket, and conducting multiple pilot studies with cohort participants.

(2) Cohort-specific documents. These resources provided more insight into the extent of processing of certain FFQ food items by highlighting information on the specific ingredients used in recipes and food preparations, the proportion by weight of individual ingredients to the final recipe or a more detailed description of food items (whether the food was canned or salted or boiled, the brand name of certain packaged foods, etc.).

(3) Supermarket scans. The ingredient lists of the first five brands of specific products that were displayed on the Walmart website in 2019 and 2020 were scrutinised. They served as a proxy for establishing the level of processing for a small proportion of food items for which limited information was available from the resources listed above.

The process of categorisation of food items at this stage was also iterative and at the end of stage four, all products were categorised into one of the four NOVA groups. The compilation and categorisation of food items from both the adult and the youth cohorts was done in Microsoft Excel (Microsoft 365 , academic license).

\section{Results}

At stage one, a total of 205 unique foods from all FFQ food lists of the NHS, NHS-II and HPFS cohorts and 315 foods in the GUTS cohort were identified and compiled. These included individual food items ('Butter'; 'Coffee'; 'Prunes'; 'White rice') and food items that were presented jointly (examples mentioned later). Ninety-seven percent of the food items in the adult cohorts ( $n 199$ of 205) and $93 \%$ in the GUTS cohort ( $n 293$ of 315) were asked in this manner. Of the multiple food items presented jointly, a large majority of them had similar grades of processing. Examples include 'Tangerines, clementines, mandarin oranges', 'English muffins, bagels, rolls', 'Shrimp, lobster, or scallops as a main dish', 'Beef, pork hotdog'. Some multiple items included specific examples of products or brand names like 'Hot breakfast cereal, like 


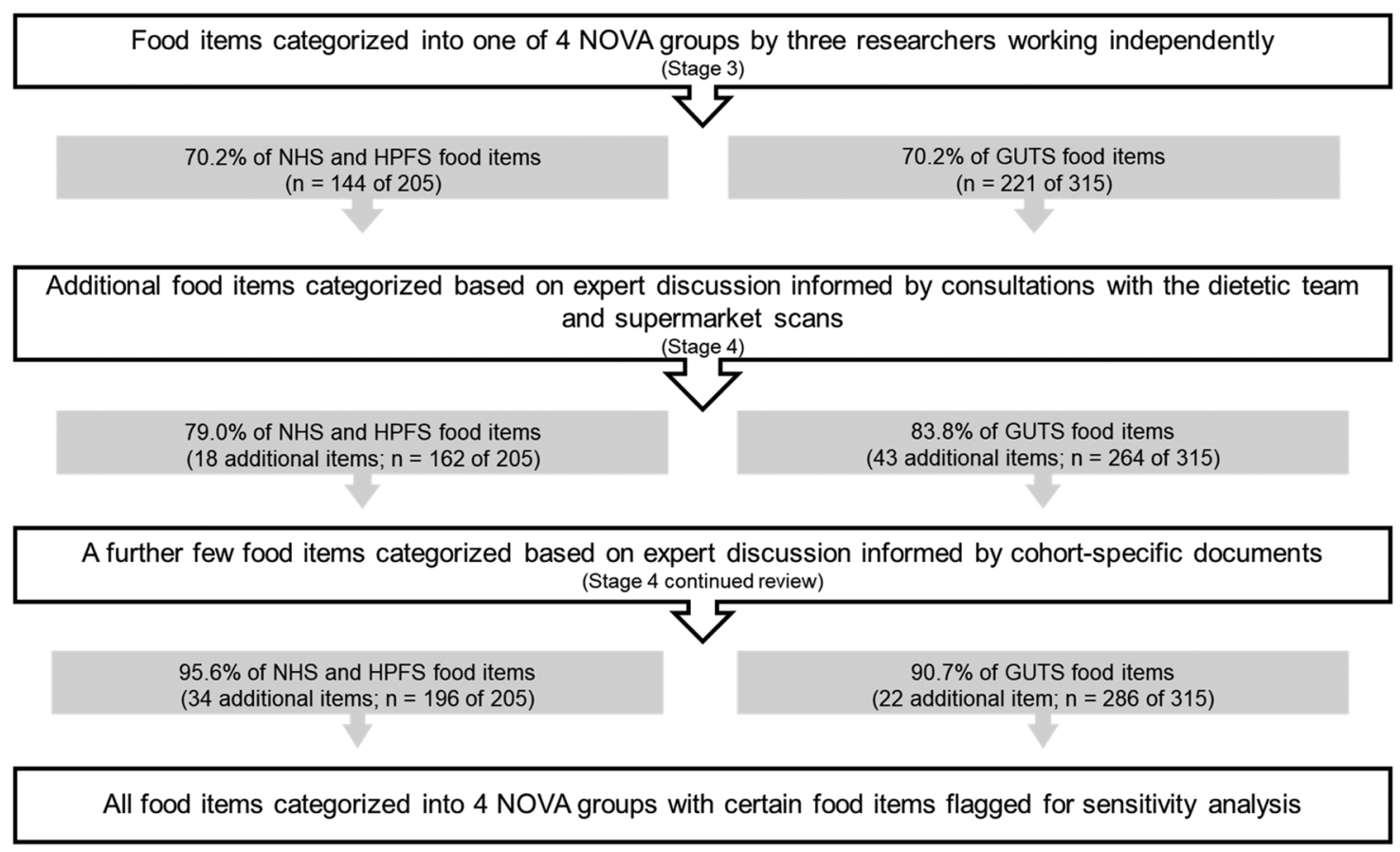

Fig. 1. The process of NOVA categorisation of food items captured by semi-quantitative food frequency questionnaires of the Nurses' Health Studies I and II (NHS), the Health Professionals follow-up study (HPFS) and the Growing Up Today Study (GUTS).

oatmeal, grits', 'Non-fat iced coffee dairy drinks, like Coffee Coolatta, Frappuccino', 'Cereal/Granola bar like Nature Valley, Quaker, or Special K'. However, about 3\% $n 6$ of 205) of the grouped food items in the NHS and the HPFS cohorts and $7 \%$ ( $n 22$ of 315 ) in the youth cohort included a combination of food items with potentially different grades of processing. For instance, in 'Jams, jellies, preserves, honey', honey would be differently processed from the other condiments. Similarly, for 'Pie, home-baked or ready-made', home-made pies would be differently processed to ready-made pies. Other examples of jointly presented food items with different grades of processing include 'Onion rings, cooked onions, or soup', 'Tofu, soyburgers, miso, edamame, or other soy dish'.

Food items were assigned to a NOVA group by three researchers in stage two. At this stage, other food items included in the FFQs specific to each cohort were also used to inform categorisation. For instance, the classification of 'Cold breakfast cereal' into G4 was informed by contextualising it relative to another item on the FFQ, 'Cooked oatmeal, oatbran' (G1), for which information was also collected in the same year. Cold cereals were assumed to be packaged and ready-to-eat, and therefore more likely to be ultraprocessed, especially as another item was capturing minimally processed oats. For food preparations containing more than one ingredient, the item description helped ascertain the level of processing of certain foods and their categorisation. Examples include 'Home-made soup without bouillon cube' (G1), 'Pie, home-baked' (G1). The descriptor 'home-made' indicated that the food item was likely to not be ultraprocessed (confirmed by the phrase 'without bouillon cube') and hence it was categorised as G1.
NOVA group assignments were triangulated in stage 3 . There was consensus among all study researchers in the categorisation of 144 of the 205 food items $(70.2 \%)$ in the adult cohorts and 221 of the 315 food items $(70 \cdot 2 \%)$ in the youth cohort (see Fig. 1). For example: 'Rice', 'Celery', 'Raw carrot' were assigned to G1; 'Butter', 'Canola oil' to G2; 'Canned tuna', 'Olives' to G3; and 'Jello', 'Ready-made soup from a can' to G4. The descriptor 'ready-made' indicated that the food item was likely to be ultra-processed. There was some uncertainty between researchers in the categorisation of 61 of the 205 food items in the adult cohorts $(29.8 \%)$ and 94 of 315 food items in the youth cohort $(29 \cdot 8 \%)$. These included all the grouped foods with a combination of products with potentially different grades of processing mentioned earlier (e.g., 'Jams, jellies, preserves, honey').

The food items with uncertain categorisation ( $n 61$ in NHS/ HPFS; $n 94$ in GUTS) were further reviewed by the expert panel in stage four. Consultations with the dietetic team followed by supermarket scans and team discussions informed the categorisation of eighteen of the sixty-one food items in the adult cohorts and forty-three of the ninety-four food items in the GUTS cohorts. These were subsequently assigned to a NOVA group. At this juncture, $79 \%$ and $83.8 \%$ of the food items from the adult and youth cohorts respectively, had been categorised. Sixteen of the eighteen foods in the NHS and HPFS cohorts and twenty-five of the forty-three in the GUTS cohort were identified as having a low potential for contributing to the ultra-processed proportion of the diet in all possible scenarios of categorisation, these products would have been assigned to either the minimally processed or the processed groups. Examples include: 'Apricots', 'Prunes', 'Walnuts' (G1); 'Sauerkraut', 'Cottage or ricotta 

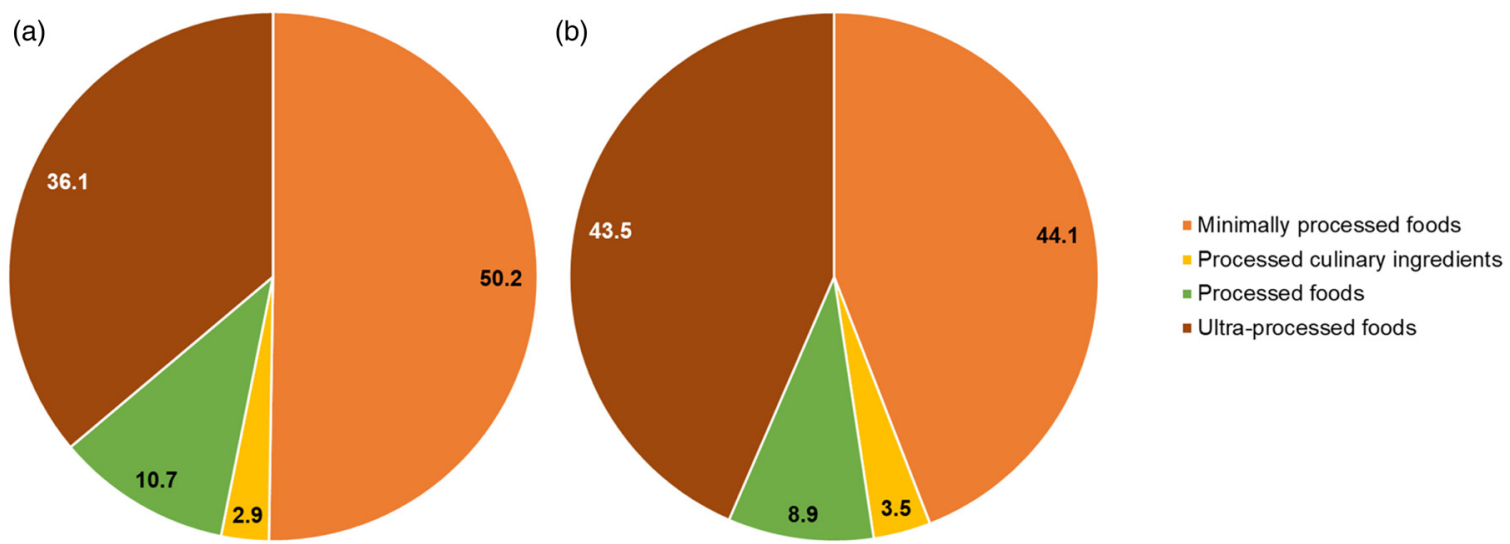

Fig. 2. The percentage contribution of the four NOVA groups to the food items compiled from all waves of the Nurses' Health Studies, the Health Professionals Follow-up Study (a), and the Growing Up Today Studies (b).

cheese', 'Mustard' (G3). The processing category for 'Mustard' (G3) was informed by the supermarket scans. Food products ( $n 2$ in NHS/HPFS; $n 18$ in GUTS) that were classified as ultra-processed at this stage included 'Salad dressing', 'Soy or Worcestershire sauce', 'Tofu, soyburgers, other meat substitutes', 'Hawaiian Punch, lemonade, Koolaid or other noncarbonated fruit drinks' and food preparations like 'Salami, bologna, or other deli meat sandwich', 'Bagels, English muffins, or rolls including breakfast sandwiches', 'Mixed other dishes (e.g., Pad Thai, chili, Frz. dinners): Beef, pork, or lamb'.

In continued review at stage four, cohort-specific documents along with further input from the dietetic team were used to determine the level of processing for thirty-four additional food items in the adult cohorts and twenty-two additional food items in the GUTS cohort. These products were subsequently assigned to a NOVA category, resulting in the categorisation of $95.6 \%$ (adult cohorts) and 90.7\% (youth cohort) of all food items. For instance, cohort-specific documents described 'Applesauce' as 'applesauce, canned, sweetened, and without salt' and 'Canned peaches' as 'peaches, canned, heavy syrup; peaches, canned in juice' which helped with their assignment into G4. The documents also provided a detailed description for items like 'French fried potatoes' (frozen French fries prepared, McDonald's French fries; Burger King French fries). Additional examples of food items that were assigned to the ultra-processed food group at this stage include food preparations like 'Brownies', 'French fried potatoes', 'Pizza', 'Chowder or cream soup', 'Dairy coffee drink', 'Danish, sweet rolls, pastry'.

There was not enough evidence in the resource documents to support the classification of the nine remaining food items in the NHS and HPFS cohorts and twenty-nine remaining food items in the GUTS cohort. After discussion with the expert panel, a conservative approach to their categorisation was adopted by assigning these products to a non-ultraprocessed NOVA group as their primary categorisation. Examples of the food items that were categorised in this manner include: 'Popcorn' (G3); 'Soya milk' (G1); 'Chicken or turkey sandwich' (G1); 'Pancakes or waffles' (G1); 'Pie, home-baked or ready-made' (G1). In the future analysis that assesses associations between ultra-processed food consumption and disease outcomes, these products would be recommended for further sensitivity analysis at which point they would be assigned to the ultra-processed group to check for robustness of the associations seen. A flow chart of the categorisation process and cumulative categorised percent is presented in Fig. 1.

A total of 74 of the 205 food items $(36 \cdot 1 \%)$ from the NHS and HPFS FFQ food lists and 137 of the 315 food items (43.5\%) from the GUTS FFQ food lists were assigned to the ultra-processed food category at the end of the categorisation process at stage 4 . Of these, $85.1 \%$ of the food items in the adult cohorts (63 of 74) and $72.9 \%$ in the youth cohort (100 of 137) were categorised at the end of stage 2, even before discussion with experts (e.g., 'Regular carbonated beverage with caffeine \& sugar', 'White bread, pita bread, or toast', 'Popsicles'). Over $86 \%$ of the ultra-processed foods from all cohorts were categorised after the first round of reviews with experts. Fig. 2 presents the contribution of the four NOVA groups to the FFQ food lists compiled from all waves of the cohorts.

Tables 1 and 2 capture the short-listed food items scrutinised at stage four.

The final NOVA classification of food items in the NHS and the HPFS cohorts is presented in Table 3. Table 4 presents the NOVA classification of the GUTS food items. The classification of the food lists of the FFQs formed the basis for the development of four different indicators that reflected participant consumption of ultra-processed foods in the cohorts - absolute kilocalories from ultra-processed foods, percentage of kilocalories from ultra-processed foods, percentage of grams of ultra-processed foods and the servings per day from ultra-processed foods.

\section{Discussion}

This article details the process of categorising food items into the four NOVA groups and identifying the ultra-processed proportion of the FFQ food lists of the NHS-I and II, the HPFS and the GUTS cohorts. Over $70 \%$ of the food items across all cohorts were assigned into one of the four NOVA groups after the first attempt at categorisation, based on published definitions that account for differences in processing between groups and 
Table 1. Foods items that required discussion and further review in the Nurses' Health Studies I and II, and the Health Professionals Follow-up Study

\begin{tabular}{|c|c|c|}
\hline All foods with discordant categorisation $n 61$ of 205 & Foods requiring additional review $n 43$ & Foods in sensitivity analysis $n 9$ \\
\hline Apple juice cider & Applesauce & Beef, pork, lamb sandwich \\
\hline Applesauce & Beans or lentils & Chicken or turkey sandwich \\
\hline Apricots & Beef, pork, lamb sandwich & Cream \\
\hline Beans or lentils & Brownies & Pancakes or waffles \\
\hline Beef, pork, lamb sandwich & Cake, home-baked & Pie, home-baked or ready-made \\
\hline Brownies & Canned peaches & Popcorn: regular \\
\hline Cake, home-baked & Canned pear & Potato chips or corn chips \\
\hline Canned peaches & Chicken or turkey sandwich & Soya milk \\
\hline Canned pear & Chowder or cream soup & Tomato sauce \\
\hline Carrots & Cookies, home-baked & \\
\hline Chicken or turkey sandwich & Cottage ricotta cheese & \\
\hline Chowder or cream soup & Cream & \\
\hline Cooked carrots & Crispbreads & \\
\hline Cookies, home-baked & Dairy coffee drink & \\
\hline Maize & French fried potatoes & \\
\hline Cottage ricotta cheese & Grapefruit juice & \\
\hline Cream & Grapefruit or grapefruit juice & \\
\hline Crispbreads & Grapefruit, grapefruit juice & \\
\hline Dairy coffee drink & Hamburger, lean or extra lean & \\
\hline French fried potatoes & Home-made sweet roll, coffee cake & \\
\hline Grapefruit juice & Jams, jellies, preserves, honey & \\
\hline Grapefruit or grapefruit juice & Orange juice & \\
\hline Grapefruit, grapefruit juice & Orange juice with calcium & \\
\hline Hamburger, lean or extra lean & Other canned fruit & \\
\hline Herbal or decaf tea & Other cheese & \\
\hline Home-made sweetroll, coffee cake & Other cooked breakfast cereal & \\
\hline Jams, jellies, preserves, honey & Other fruit juices & \\
\hline Mustard & Pancakes or waffles & \\
\hline Orange juice & Pasta & \\
\hline Orange juice with calcium & Peanut butter & \\
\hline Other canned fruit & Pie, home-baked or ready-made & \\
\hline Other cheese & Pizza & \\
\hline Other cooked breakfast cereal & Popcorn: regular & \\
\hline Other fruit juices & Potato chips or corn chips & \\
\hline Other nuts & Potatoes, baked, boiled or mashed & \\
\hline Pancakes or waffles & Pretzels & \\
\hline Pasta & Regular hamburger & \\
\hline Peanut butter & Sour cream & \\
\hline Peanuts & soya milk & \\
\hline Peas or lima beans & Tea & \\
\hline Pie, home-baked or ready-made & Tofu or soyabeans & \\
\hline Pizza & Tomato sauce & \\
\hline Popcorn: regular & Tortillas & \\
\hline \multicolumn{3}{|l|}{ Potato chips or corn chips } \\
\hline \multicolumn{3}{|l|}{ Potatoes, baked, boiled or mashed } \\
\hline \multicolumn{3}{|l|}{ Pretzels } \\
\hline \multicolumn{3}{|l|}{ Prunes } \\
\hline \multicolumn{3}{|l|}{ Regular hamburger } \\
\hline \multicolumn{3}{|l|}{ Salad dressing } \\
\hline \multicolumn{3}{|l|}{ Sauerkraut } \\
\hline \multicolumn{3}{|l|}{ Sour cream } \\
\hline \multicolumn{3}{|l|}{ Soya milk } \\
\hline \multicolumn{3}{|l|}{ Tea } \\
\hline \multicolumn{3}{|l|}{ Tofu or soyabeans } \\
\hline \multicolumn{3}{|l|}{ Tomato sauce } \\
\hline \multicolumn{3}{|l|}{ Tortillas } \\
\hline \multicolumn{3}{|l|}{ Walnuts } \\
\hline \multicolumn{3}{|l|}{ Yogurt } \\
\hline \multicolumn{3}{|l|}{ Yogurt-plain, low-carb } \\
\hline \multicolumn{3}{|l|}{ Plain or carbonated water } \\
\hline Soya or Worcestershire sauce & & \\
\hline
\end{tabular}

their accompanying example products. The approach to classifying the remaining $30 \%$ of food items involved discussions with experts that were informed by insights from the research dieticians, information provided by cohort-specific documents and scans of online grocery stores.
A conservative approach to the classification of some of the more challenging food items was adopted. This meant that only food items that could be justifiably considered ultra-processed based on information from cohort-specific documents were assigned to this NOVA group. The nutrient 
Table 2. Foods items that required discussion and further review in the Growing Up Today Study

All foods with discordant categorisation $n 94$ of 315

Apple juice and other fruit juices

Apples or applesauce

Bagels, English muffins or rolls include breakfast sandwiches

Baked chips, e.g., baked lays

Beans or lentils include baked beans

Beef (steak, roast) or lamb as main dish

Brownies

Burrito: beans

Burrito: beef or pork

Burrito: chicken or turkey

Burrito: tofu

Burrito: vegetables

Cake

Cheese

Cheeseburger

Chicken or turkey as main dish

Chicken or turkey sandwich

Clear soup (with rice, noodles, vegetables)

Coffee - not decaf

Coleslaw

Cookies

Corn chips/Doritos

Corn chips/Doritos

Cornbread

Cornbread

Cottage or ricotta cheese

Cream (milk) soups or chowder

Danish, sweetrolls, pastry

Donuts

Eggrolls

Fish sticks, fish cakes or fish sandwich

French fries

French toast

French toast

Fruit drinks/pouch, lemonade, Sunny D, Koolaid, sugared ice tea or other non-carbonated fruit drink - NOT juice

Fruit drinks/punch, lemonade, Sunny D, Koolaid or other non-carbonated fruit drink (No juice)

Grilled cheese

Hamburger

Hawaiian Punch, lemonade, Koolaid or other non-carbonated fruit drink

Hawaiian Punch, lemonade, sport \& fruit drinks

Jams, jellies, preserves, syrup, honey or fluff exclude sandwiches

Lasagne/baked ziti/ravioli

Liver

Macaroni and cheese

Mixed other dishes (e.g., Pad Thai, chili, Frz. dinners): beef, pork or lamb

Mixed other dishes (e.g., Pad Thai, chili, Frz. dinners): chicken or turkey

Mixed other dishes (e.g., Pad Thai, chili, Frz. dinners): fish

Mixed other dishes (e.g., Pad Thai, chili, Frz. dinners): tofu

Mixed other dishes (e.g., Pad Thai, chili, Frz. dinners): vegetables

Noodles, pasta

Onion rings, cooked onions or soup (1/2 cup)

Orange juice

Pancakes or waffles

Pancakes or waffles or French toast

Pancakes or waffles

Peaches, plums, apricots (fresh, canned or dried)

Peanut butter sandwich (plain or with jelly, fluff, etc.)

Peanuts, nuts

Peas or lima beans (fresh, frozen, canned) or soup
Foods requiring additional review $n 51$

Foods in sensitivity analysis $n 29$

Apples or applesauce

Baked chips, e.g., baked lays

Brownies

Burrito: beans

Burrito: beef or pork

Burrito: chicken or turkey

Burrito: tofu

Burrito: vegetables

Cake

Cheeseburger

Chicken or turkey sandwich

Clear soup (with rice, noodles, vegetables)

Coleslaw

Cookies

Corn chips/Doritos

Corn chips/Doritos

Cornbread

Cornbread

Cream (milk) soups or chowder

Danish, sweet rolls, pastry

Doughnuts

French fries

French toast

French toast

Grilled cheese

Hamburger

Lasagne/baked ziti/ravioli

Macaroni and cheese

Pancakes or waffles

Pancakes or waffles or French toast

Pancakes or waffles

Peanut butter sandwich (plain or with jelly, fluff, etc.)

Pie

Pizza

Popcorn

\section{Potato chips}

Pudding

Regular potato chips, corn chips, Doritos

Roast beef or ham sandwich

Sandwich or wrap: beef

Sandwich or wrap: chicken or turkey

Sandwich or wrap: tuna

Sandwich or wrap: veggie (no meat)

Spaghetti with tomato sauce

Tacos/burritos/enchiladas - beans

Tacos/burritos/enchiladas - beef

Tacos/burritos/enchiladas - beef and beans

Tacos/burritos/enchiladas - chicken

Tea - hot or iced

Tomato sauce, e.g., spaghetti sauce

Tuna sandwich
Apples or applesauce

Baked chips, e.g., baked lays

Cake

Chicken or turkey sandwich

Clear soup (with rice, noodles, vegetables)

Corn chips/Doritos

Corn chips/Doritos

Cornbread

Cornbread

French toast

French toast

Grilled cheese

Lasagne/baked ziti/ravioli

Pancakes or waffles

Pancakes or waffles or French toast Pancakes or waffles

Pie

Popcorn

Potato chips

Pudding

Regular potato chips, corn chips, Doritos

Roast beef or ham sandwich

Sandwich or wrap: beef

Sandwich or wrap: chicken or turkey

Sandwich or wrap: tuna

Sandwich or wrap: veggie (no meat)

Tea - hot or iced

Tomato sauce, e.g., spaghetti sauce Tuna sandwich 
Table 2. Continued

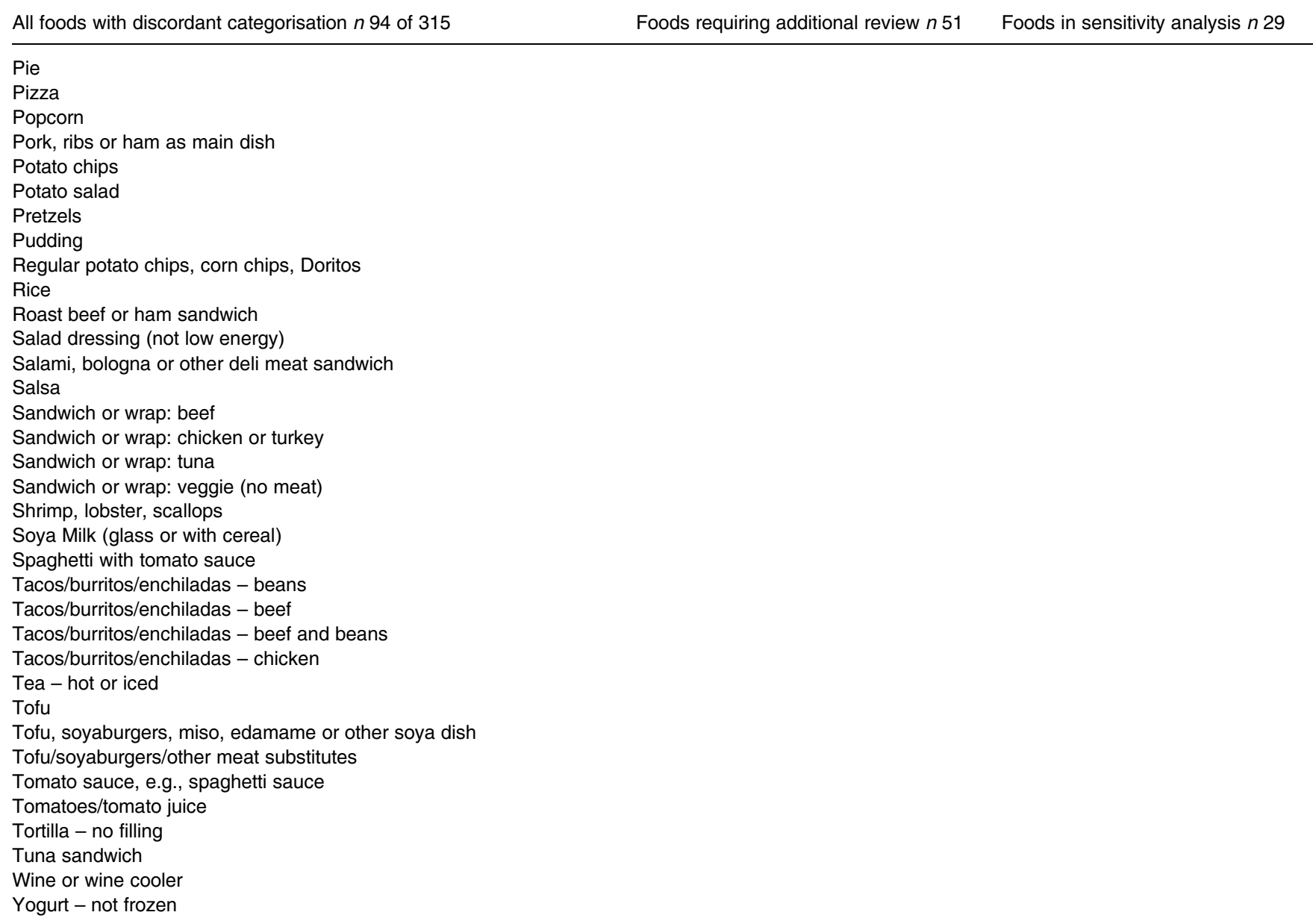

composition of the product was never considered in the categorisation process. In the handful of instances of uncertainty, a non-ultra-processed NOVA group was assigned as the primary classification and the food items were flagged for future sensitivity analysis where they could be re-categorised as ultra-processed. It is therefore reasonable to assume that the ultra-processed foods may be underestimated, and caution is needed in the interpretation of the future absolute intake of ultra-processed foods estimated from these FFQs. While this may have an attenuating effect on any future diet-disease relationship studied, the recategorisation planned for sensitivity analyses will help measure the variability associated with this approach.

Besides the resources mentioned in this article to help with the NOVA categorisation of dietary data, additional resources may be considered. Since there is no one gold-standard for applying the NOVA categorisation, the use of yearappropriate, context- or region-specific nationally representative surveys that use 24-h diet recalls or diet records could be used to gather more detailed information on dietary intake. The food items from these surveys could help determine the level of processing of certain challenging products. For instance, the National Health and Nutrition Examination Surveys (NHANES) in the US could be used to provide some insight into the processing grade of certain challenging foods if there was no access to cohort-specific resources. Information on complementary aspects of participant dietary behaviour like their frequency of eating out, purchase of branded packaged foods, perceived consumption of branded products, etc., may also be used to corroborate the NOVA classification of their diet. Previously, researchers have used participant report of percentage of brands of ultra-processed foods and home-made foods to resolve uncertainty and reach consensus in categorising dietary data collected using 24-h diet records ${ }^{(20)}$. This additional information was used after all consumed food items had been categorized according to NOVA by study dietitians and reviewed by an expert panel.

Alternative approaches were considered but not implemented. In the present approach, composite food preparations with multiple ingredients were considered in their entirety when being assigned to a NOVA group, informed by key information contained in their item descriptions (home-made, ready-made, takeaway, frozen, etc.), along with information of the ingredient lists of equivalent products from the websites of leading retailers. Alternatively, home-made composite dishes could be divided into their ingredients and the individual ingredients could then be assigned to a NOVA group. Another alternative approach might classify food items into more than one NOVA group with appropriate resources justifying the allocation of a percentage of the food item into 
Table 3. The classification of all food items captured by the semi-quantitative food frequency questionnaires of the Nurses' Health Studies I and II, and the Health Professionals follow-up study, into the NOVA groups of minimally processed foods (1), processed culinary ingredients (2), processed foods (3), and ultra-processed foods (4)

\begin{tabular}{|c|c|}
\hline Food item & $\begin{array}{l}\text { NOVA group } \\
\text { assignment }\end{array}$ \\
\hline 1-2\% Milk & 1 \\
\hline Alfafa sprouts & 1 \\
\hline Apple juice cider & 3 \\
\hline Applesauce & 4 \\
\hline Apricots & 1 \\
\hline Avocado & 1 \\
\hline Bacon & 4 \\
\hline Banana & 1 \\
\hline Beans or lentils & 1 \\
\hline Beef, calf, pork liver & 1 \\
\hline Beef, lamb as a main dish & 1 \\
\hline Beef, pork hot dogs & 4 \\
\hline Beef, pork, lamb sandwich ${ }^{a}$ & $1^{\mathrm{a}}$ \\
\hline Beer & 3 \\
\hline Beets & 1 \\
\hline Blueberries & 1 \\
\hline Breaded fish cakes, pieces, sticks & 4 \\
\hline Breakfast bar & 4 \\
\hline Broccoli & 1 \\
\hline Brown rice & 1 \\
\hline Brownies & 4 \\
\hline Brussels sprouts & 1 \\
\hline Butter & 2 \\
\hline Caffeine-free coke pepsi & 4 \\
\hline Cake, home-baked & 1 \\
\hline Cake, ready-made & 4 \\
\hline Candy bar with chocolate & 4 \\
\hline Candy bar without chocolate & 4 \\
\hline Canned peaches & 4 \\
\hline Canned pear & 4 \\
\hline Canned tuna & 3 \\
\hline Cantaloupe & 1 \\
\hline Carrots & 1 \\
\hline Cauliflower & 1 \\
\hline Celery & 1 \\
\hline Chicken or turkey hot dogs & 4 \\
\hline Chicken or turkey liver & 1 \\
\hline Chicken or turkey sandwich ${ }^{\mathrm{a}}$ & $1^{\mathrm{a}}$ \\
\hline Chicken or turkey, with skin & 1 \\
\hline Chicken or turkey, without skin & 1 \\
\hline Chocolate bars & 4 \\
\hline Chowder or cream soup & 4 \\
\hline Coffee & 1 \\
\hline Coke, Pepsi cola & 4 \\
\hline Cold breakfast cereal & 4 \\
\hline Cooked cabbage & 1 \\
\hline Cooked carrots & 1 \\
\hline Cooked oatmeal, oatbran & 1 \\
\hline Cookies, brownie ready-made & 4 \\
\hline Cookies, fat free, reduced fat & 4 \\
\hline Cookies, home-baked & 1 \\
\hline Maize & 1 \\
\hline Cottage ricotta cheese & 3 \\
\hline Cream $^{a}$ & $2^{\mathrm{a}}$ \\
\hline Cream cheese & 4 \\
\hline Crispbreads & 3 \\
\hline Cucumber & 1 \\
\hline Dairy coffee drink & 4 \\
\hline Dark chocolate bars & 4 \\
\hline Dark meat fish & 1 \\
\hline Decaffeinated coffee & 1 \\
\hline Diet nutrition drinks, Slimfast & 4 \\
\hline
\end{tabular}

Table 3. Continued

\begin{tabular}{|c|c|}
\hline Food item & $\begin{array}{l}\text { NOVA group } \\
\text { assignment }\end{array}$ \\
\hline Doughnuts & 4 \\
\hline Dried cranberries & 1 \\
\hline Eggplant, zucchini, summer squash & 1 \\
\hline Energy bar & 4 \\
\hline Energy or high protein bars & 4 \\
\hline English muffins, bagels, rolls & 4 \\
\hline $\begin{array}{l}\text { Ensure, boost or other meal replacement } \\
\text { drinks }\end{array}$ & 4 \\
\hline Fat free popcorn & 4 \\
\hline Fat free, light crackers & 4 \\
\hline Figs & 1 \\
\hline Flavoured yogurt without Nutrasweet & 4 \\
\hline French fried potatoes & 4 \\
\hline Fresh apples, pears & 1 \\
\hline Fresh pears & 1 \\
\hline Frozen yogurt, sherbet, ice cream & 4 \\
\hline Garlic & 1 \\
\hline Grapefruit & 1 \\
\hline Grapefruit juice & 1 \\
\hline Grapefruit or grapefruit juice & 1 \\
\hline Green, red peppers & 1 \\
\hline Hamburger, lean or extra lean & 1 \\
\hline Hawaiian punch & 4 \\
\hline Herbal or decaf tea & 1 \\
\hline High-protein, low-carb candy bar & 4 \\
\hline Home-made soup with bouillon & 4 \\
\hline Home-made soup without bouillon cube & 1 \\
\hline Home-made sweetroll, coffee cake & 1 \\
\hline Hummus & 3 \\
\hline Ice cream & 4 \\
\hline Iceberg or head lettuce & 1 \\
\hline Jams, jellies, preserves, honey & 4 \\
\hline Kale, mustard or chard green & 1 \\
\hline Ketchup or red chili sauce & 4 \\
\hline Light beer & 3 \\
\hline Liquor & 4 \\
\hline Low-energy soda, caffeine free & 4 \\
\hline Low-energy soda, Pepsi, 7-up & 4 \\
\hline Low-fat, fat-free mayonnaise & 4 \\
\hline Margarine & 4 \\
\hline Mixed dried fruit & 1 \\
\hline Mixed dried fruits & 1 \\
\hline Mixed vegetables & 1 \\
\hline Muffins or biscuits & 4 \\
\hline Mushrooms & 1 \\
\hline Mustard & 3 \\
\hline Non-dairy whitener & 4 \\
\hline Nutrasweet or Equal & 4 \\
\hline Oat bran & 1 \\
\hline Oil and vinegar dressing & 2 \\
\hline Olive oil added to food & 2 \\
\hline Olives & 3 \\
\hline Omega-3 fortified including yolk & 1 \\
\hline Onion as a garnish & 1 \\
\hline Onion as a vegetable & 1 \\
\hline Orange juice & 1 \\
\hline Orange juice with calcium & 1 \\
\hline Orange squash & 1 \\
\hline Oranges & 1 \\
\hline Other artificial sweetener & 4 \\
\hline Other bran & 1 \\
\hline Other canned fruit & 3 \\
\hline Other carbon beverage & 4 \\
\hline Other cheese & 3 \\
\hline Other cooked breakfast cereal & 1 \\
\hline Other fish & 1 \\
\hline
\end{tabular}


Table 3. Continued

\begin{tabular}{|c|c|}
\hline Food item & $\begin{array}{l}\text { NOVA group } \\
\text { assignment }\end{array}$ \\
\hline Other fruit juices & 1 \\
\hline Other grains & 1 \\
\hline Other low energy carb & 4 \\
\hline Other low energy cola with caffeine & 4 \\
\hline Other nuts & 1 \\
\hline Pancakes or waffles ${ }^{a}$ & $1^{\mathrm{a}}$ \\
\hline Pasta & 1 \\
\hline Peach, apricots, plums & 1 \\
\hline Peanut butter & 3 \\
\hline Peanuts & 1 \\
\hline Peas or lima beans & 1 \\
\hline Pepper & 1 \\
\hline Pie, home-baked & 1 \\
\hline Pie, home-baked or ready-made ${ }^{a}$ & $1^{a}$ \\
\hline Pie, ready-made & 4 \\
\hline Pizza & 4 \\
\hline Plain or carbonated water & 1 \\
\hline Popcorn: regular ${ }^{\mathrm{a}}$ & $3^{a}$ \\
\hline Pork as a main dish & 1 \\
\hline Potato chips or corn chips ${ }^{a}$ & $3^{a}$ \\
\hline Potatoes, baked, boiled or mashed & 1 \\
\hline Pretzels & 3 \\
\hline Processed meats, sausage & 4 \\
\hline Prune juice & 1 \\
\hline Prunes & 1 \\
\hline Raisins or grapes & 1 \\
\hline Raw carrots & 1 \\
\hline Ready-made soup from can & 4 \\
\hline Ready-made sweetroll, coffeecake & 4 \\
\hline Red chili sauce & 4 \\
\hline Red wine & 3 \\
\hline Regular crackers & 4 \\
\hline Regular hamburger & 1 \\
\hline Regular mayonnaise & 4 \\
\hline Romaine or leaf lettuce & 1 \\
\hline Rye, pumpernickel bread & 4 \\
\hline Salad dressing & 4 \\
\hline Salami, bologna, processed meat sandwiches & 4 \\
\hline Salsa, picante, taco sauce & 4 \\
\hline Salt & 2 \\
\hline Sauerkraut & 3 \\
\hline Shrimp lobster scallop & 1 \\
\hline Skim or low-fat milk & 1 \\
\hline Snack bars & 4 \\
\hline Sour cream & 2 \\
\hline Soya milk & $1^{a}$ \\
\hline Soya or Worcestershire sauce & 4 \\
\hline Spinach, cooked & 1 \\
\hline Spinach, raw & 1 \\
\hline Splena & 4 \\
\hline Spreadable butter & 4 \\
\hline Strawberries & 1 \\
\hline String beans & 1 \\
\hline Sweetroll fat free or reduced fat & 4 \\
\hline Tangerines, clementines, mandarin oranges & 1 \\
\hline Tea & 1 \\
\hline Toasted breads, bagel or English muffin & 4 \\
\hline Tofu or soyabeans & 3 \\
\hline Tomato juice & 3 \\
\hline Tomato sauce ${ }^{\mathrm{a}}$ & $3^{a}$ \\
\hline Tomato soup & 4 \\
\hline Tomatoes & 1 \\
\hline Tortillas & 3 \\
\hline Uncooked cabbage, coleslaw & 1 \\
\hline Walnuts & 1 \\
\hline Watermelon & 1 \\
\hline
\end{tabular}

Continued
Table 3. Continued

\begin{tabular}{ll}
\hline Food item & $\begin{array}{l}\text { NOVA group } \\
\text { assignment }\end{array}$ \\
\hline Wheat germ & 1 \\
White bread & 4 \\
White rice & 1 \\
White wine & 3 \\
Whole eggs & 1 \\
Whole milk & 1 \\
Whole wheat - whole grain bread & 4 \\
Yams or sweet potatoes & 1 \\
Yogurt & 1 \\
Yogurt artificially sweetened & 4 \\
Yogurt flavoured without nutrasweet & 4 \\
Yogurt-plain, low-carb & 1 \\
\hline a Indicates foods to be categorised as ultra-processed (4) for sensitivity analysis.
\end{tabular}

each group. For instance, 'Pie, home-baked or ready-made' could be split to allocate $60 \%$ of its nutrient profile to the minimally processed group and $40 \%$ to the ultra-processed group. This approach of dividing the nutrient profile of the food item into more than one NOVA group has been done before $^{(6,21)}$. It may either be an equal split between different NOVA groups or be divided in a proportion that is informed by other sources ${ }^{(21)}$. Validation studies will be needed to estimate the misclassification minimised in determining the ultra-processed foods by these approaches.

Once validated, this approach could be used in future studies to minimise the misclassification associated with estimating the ultra-processed fraction of the diet and could help assess diet-disease relationships more accurately. It could also be used to identify ultra-processed foods from databases that contain information on dietary intake, food product acquisition, or food item sales. The identification of specific barriers faced at each stage of the categorisation process could be used to inform data-driven algorithms categorising dietary intake and inform the refinement of existing dietary assessment instruments to more accurately reflect the level of processing of food items. Including specific information in dietary assessment instruments on the processing of certain food items (e.g., 'home-made from scratch'), including brand names of packaged products where possible (for branded breakfast cereal and breads for instance), capturing the place of preparation (at restaurant, street-food, take-aways), as well as the manner of preparation of mixed dishes and the types of ingredients used (e.g., 'from scratch with fresh ingredients', 'pre-made and frozen using processed ingredients') would make identifying the level of processing of food items easier ${ }^{(22)}$. For FFQs, it could also mean adding more items or sub-dividing existing ones to differentiate between grades of processing and asking follow-up questions that give a better sense of the overall processing of the dietary pattern ${ }^{(23)}$.

Finally, this work may serve as a protocol for applying the NOVA classification and identifying ultra-processed foods in other large-scale cohort studies. While it presents a specific example of an approach for the classification of FFQ food item, the various stages and the decision-points detailed in this manuscript could be modified based on context-specific 
Table 4. The classification of all food items captured by the semi-quantitative food frequency questionnaires of the Growing Up Today Study, into the NOVA groups of minimally processed foods (1), processed culinary ingredients (2), processed foods (3) and ultra-processed foods (4)

\begin{tabular}{|c|c|}
\hline Food item & $\begin{array}{l}\text { NOVA group } \\
\text { assignment }\end{array}$ \\
\hline 1 or $2 \%$ milk & 1 \\
\hline $1 \%$ milk & 1 \\
\hline $2 \%$ milk & 1 \\
\hline Added sugar & 2 \\
\hline Apple juice, other $100 \%$ fruit juices & 1 \\
\hline Apple juice and other $100 \%$ fruit juices & 1 \\
\hline Apple juice and other fruit juices & 1 \\
\hline Apples or applesauce & $1^{\mathrm{a}}$ \\
\hline Apples or pears & 1 \\
\hline Applesauce & 4 \\
\hline Bacon & 4 \\
\hline Bacon & 4 \\
\hline $\begin{array}{l}\text { Bagels, English muffins or rolls include breakfast } \\
\text { sandwiches }\end{array}$ & 4 \\
\hline Baked chips, e.g., Baked Lays & $3^{\mathrm{a}}$ \\
\hline Bananas & 1 \\
\hline Beans or lentils including baked beans & 1 \\
\hline Beans/lentils/edamame & 1 \\
\hline Beans/lentils/soybeans & 1 \\
\hline Beef (steak, roast) or lamb as main dish & 1 \\
\hline $\begin{array}{l}\text { Beef or lamb as a main dish, e.g., as a steak or } \\
\text { roast }\end{array}$ & 1 \\
\hline Beef or pork hot dogs & 4 \\
\hline Beef, pork or lamb fat & 1 \\
\hline Beef/pork sausage & 4 \\
\hline Beer & 3 \\
\hline Beer, regular & 3 \\
\hline Beets (not greens) & 1 \\
\hline Biscuit & 4 \\
\hline Biscuit/roll & 4 \\
\hline Breakfast bars, e.g., Nutrigrain, granola, Kashi & 4 \\
\hline Broccoli & 1 \\
\hline Broccoli & 1 \\
\hline Brown gravy & 4 \\
\hline Brown rice & 1 \\
\hline Brownies & 4 \\
\hline Brussels sprouts & 1 \\
\hline Burrito: beans & 4 \\
\hline Burrito: beef or pork & 4 \\
\hline Burrito: chicken or turkey & 4 \\
\hline Burrito: tofu & 4 \\
\hline Burrito: vegetables & 4 \\
\hline Butter & 2 \\
\hline Butter - not margarine & 2 \\
\hline Cake & $1^{\mathrm{a}}$ \\
\hline Cake or snack cakes, e.g., Twinkies & 4 \\
\hline Canned tuna & 3 \\
\hline Canola oil & 2 \\
\hline Cantaloupe & 1 \\
\hline Cantaloupe, melons & 1 \\
\hline $\begin{array}{l}\text { Carbonated, low-cal 'diet' beverage with caffeine } \\
\text { (e.g., Diet Coke) }\end{array}$ & 4 \\
\hline Carrots, cooked & 1 \\
\hline Carrots, cooked & 1 \\
\hline Carrots, raw & 1 \\
\hline Carrots, raw & 1 \\
\hline Celery & 1 \\
\hline Celery & 1 \\
\hline $\begin{array}{l}\text { Cereal/Granola bar, like Nature Valley, Quaker or } \\
\text { Special K }\end{array}$ & 4 \\
\hline Cheese & 3 \\
\hline
\end{tabular}

Table 4. Continued

\begin{tabular}{|c|c|}
\hline Food item & $\begin{array}{l}\text { NOVA group } \\
\text { assignment }\end{array}$ \\
\hline $\begin{array}{l}\text { Cheese, eaten alone or added to main dish, } \\
\text { sandwich or quesadilla }\end{array}$ & 3 \\
\hline Cheeseburger & 4 \\
\hline Chicken nuggets & 4 \\
\hline $\begin{array}{l}\text { Chicken or turkey as a main dish (e.g., fried or } \\
\text { roasted) with skin, including grounded }\end{array}$ & 1 \\
\hline Chicken or turkey as a main dish, without skin & 1 \\
\hline Chicken or turkey as main dish & 1 \\
\hline Chicken or turkey hot dogs or sausages & 4 \\
\hline Chicken or turkey sandwich & $1^{\mathrm{a}}$ \\
\hline Chicken or turkey skin & 1 \\
\hline Chocolate like Hershey's or M \& M's & 4 \\
\hline $\begin{array}{l}\text { Chocolate candy like Hershey's, Snickers or M \& } \\
\text { M's }\end{array}$ & 4 \\
\hline Chocolate candy like Snickers or M \& M's & 4 \\
\hline Chocolate milk & 4 \\
\hline Chocolate milk or any flavoured milk & 4 \\
\hline Chocolate or other flavoured milk & 4 \\
\hline Chocolate, e.g., Hershey's or M\&M's & 4 \\
\hline Clear soup (with rice, noodles, vegetables) & $3^{a}$ \\
\hline Coffee - not decaf. & 1 \\
\hline $\begin{array}{l}\text { Coffee drinks - latte, Coolers, Coolatas, } \\
\text { Frappuccinos, Mochachinos }\end{array}$ & 4 \\
\hline Cold breakfast cereal & 4 \\
\hline Cold breakfast cereal & 4 \\
\hline Coleslaw & 4 \\
\hline Collard greens/kale & 1 \\
\hline Collard greens/kale/cooked spinach & 1 \\
\hline Cooked oatmeal, including instant & 1 \\
\hline Cookies & 4 \\
\hline Maize & 1 \\
\hline Maize & 1 \\
\hline Corn chips/Doritos & $3^{a}$ \\
\hline Corn oil & 2 \\
\hline Cornbread & $3^{a}$ \\
\hline Cornbread & 3 \\
\hline Cottage cheese & 3 \\
\hline Cottage or ricotta cheese & 3 \\
\hline Crackers, e.g., Cheez-its or Ritz & 4 \\
\hline Crackers, like Wheat Thins or Ritz & 4 \\
\hline Cream (milk) soups or chowder & 1 \\
\hline Cream cheese & 4 \\
\hline Cream cheese & 4 \\
\hline Cream, e.g., coffee, sour (exclude fat free) & 2 \\
\hline Danish, donut, sweetroll or pastry & 4 \\
\hline Danish, sweetrolls, pastry & 4 \\
\hline Dark bread & 4 \\
\hline $\begin{array}{l}\text { Dark meat fish, e.g., tuna steak, salmon, sardines, } \\
\text { swordfish }\end{array}$ & 1 \\
\hline Decaffeinated coffee & 1 \\
\hline Diet soda & 4 \\
\hline Donuts & 4 \\
\hline Eggrolls & 1 \\
\hline Eggs & 1 \\
\hline Eggs, e.g., scrambled, fried, in breakfast sandwich & 1 \\
\hline Energy bar (like Power or Cliff Bar) & 4 \\
\hline Energy bar, e.g., Powerbar, Clif Bar, Lunabar & 4 \\
\hline $\begin{array}{l}\text { Energy drink - (e.g., Red Bull), Regular energy } \\
\text { drinks }\end{array}$ & 4 \\
\hline $\begin{array}{l}\text { Energy drink - (e.g., Red Bull), Sugar free, low } \\
\text { energy or low carb energy drinks }\end{array}$ & 4 \\
\hline Energy drink - Red Bull, Rock Star & 4 \\
\hline English muffins or bagels & 4 \\
\hline Fish sticks, fish cakes or fish sandwich & 4 \\
\hline French fries & 4 \\
\hline French fries & 4 \\
\hline
\end{tabular}


Table 4. Continued

\begin{tabular}{|c|c|}
\hline Food item & $\begin{array}{l}\text { NOVA group } \\
\text { assignment }\end{array}$ \\
\hline French toast & $1^{\mathrm{a}}$ \\
\hline Fresh fish as main dish & 1 \\
\hline Frozen yogurt & 4 \\
\hline Frozen yogurt or low-fat ice cream & 4 \\
\hline $\begin{array}{l}\text { Fruit drinks/pouch, lemonade, Sunny D, Koolaid, } \\
\text { sugared ice tea or other non-carbonated fruit } \\
\text { drink - NOT juice }\end{array}$ & 4 \\
\hline Fruit snacks or fruit rollups & 4 \\
\hline Fun fruit or fruit rollups & 4 \\
\hline Graham crackers & 4 \\
\hline Grapes & 1 \\
\hline Green/red peppers & 1 \\
\hline Green/red/yellow peppers & 1 \\
\hline Greens/kale & 1 \\
\hline Grilled cheese & $3^{a}$ \\
\hline Hamburger & 4 \\
\hline $\begin{array}{l}\text { Hawaiian Punch, lemonade, Koolaid or other } \\
\text { non-carbonated fruit drink }\end{array}$ & 4 \\
\hline Hawaiian Punch, lemonade, sport \& fruit drinks & 4 \\
\hline High protein bar (like MetRx or Balance Bar) & 4 \\
\hline High protein bar, e.g., Zone or Balance Bar & 4 \\
\hline High protein shake or drink, e.g., whey or soya & 4 \\
\hline Hot breakfast cereal, like oatmeal, grits & 1 \\
\hline Hot dogs & 4 \\
\hline Hot tea & 1 \\
\hline Ice cream & 4 \\
\hline Ice cream & 4 \\
\hline Iced tea - sweetened & 4 \\
\hline Instant Breakfast & 4 \\
\hline Instant breakfast drink & 4 \\
\hline Instant Breakfast Drink/High Protein Shake or Drink & 4 \\
\hline $\begin{array}{l}\text { Jams, jellies, preserves, syrup, honey or fluff, } \\
\text { exclude sandwiches }\end{array}$ & 4 \\
\hline Jello & 4 \\
\hline Ketchup & 4 \\
\hline Ketchup & 4 \\
\hline Lasagne/baked ziti/ravioli & $1^{\mathrm{a}}$ \\
\hline Lettuce/tossed salad & 1 \\
\hline Lettuce/tossed salad & 1 \\
\hline Light beer, e.g., Bud Light or Natural Light & 3 \\
\hline Liquor, like vodka or rum & 4 \\
\hline Liver & 1 \\
\hline Low energy or low-fat salad dressing & 3 \\
\hline Low energy or low-fat salad dressing & 3 \\
\hline $\begin{array}{l}\text { Low-fat or whole milk coffee dairy drinks, e.g., } \\
\text { Cappuccino, Mocha, Latte }\end{array}$ & 4 \\
\hline $\begin{array}{l}\text { Low-fat or whole milk iced coffee dairy drinks, e.g., } \\
\text { Coffee Coolatta, Frappuccino }\end{array}$ & 4 \\
\hline Macaroni and cheese & 1 \\
\hline Margarine - not butter & 4 \\
\hline Mayonnaise & 4 \\
\hline Mayonnaise & 4 \\
\hline Meatballs or meatloaf & 1 \\
\hline Milk & 1 \\
\hline Milkshake or frappe & 4 \\
\hline $\begin{array}{l}\text { Mixed other dishes (e.g., Pad Thai, chili, Frz. } \\
\text { dinners): beef, pork or lamb }\end{array}$ & 4 \\
\hline $\begin{array}{l}\text { Mixed other dishes (e.g., Pad Thai, chili, Frz. } \\
\text { dinners): chicken or turkey }\end{array}$ & 4 \\
\hline $\begin{array}{l}\text { Mixed other dishes (e.g., Pad Thai, chili, Frz. } \\
\text { dinners): fish }\end{array}$ & 4 \\
\hline $\begin{array}{l}\text { Mixed other dishes (e.g., Pad Thai, chili, Frz. } \\
\text { dinners): tofu }\end{array}$ & 4 \\
\hline $\begin{array}{l}\text { Mixed other dishes (e.g., Pad Thai, chili, Frz. } \\
\text { dinners): vegetables }\end{array}$ & 4 \\
\hline Mixed vegetables & 1 \\
\hline
\end{tabular}

Table 4. Continued

\begin{tabular}{|c|c|}
\hline Food item & $\begin{array}{l}\text { NOVA group } \\
\text { assignment }\end{array}$ \\
\hline Mixed vegetables & 1 \\
\hline Muffin & 4 \\
\hline Nachos with cheese & 4 \\
\hline $\begin{array}{l}\text { Non-fat coffee dairy drinks, e.g., Cappuccino, } \\
\text { Mocha, Latte }\end{array}$ & 4 \\
\hline $\begin{array}{l}\text { Non-fat iced coffee dairy drinks, e.g., Coffee } \\
\text { Coolatta, Frappuccino }\end{array}$ & 4 \\
\hline Noodles, pasta & 1 \\
\hline Oatmeal & 1 \\
\hline $\begin{array}{l}\text { Oatmeal and other hot breakfast cereal, like farina, } \\
\text { grits }\end{array}$ & 1 \\
\hline Olive Oil & 2 \\
\hline Onion rings, cooked onions or soup & 1 \\
\hline Onions as a garnish or in salad & 1 \\
\hline Orange juice & 1 \\
\hline Orange juice & 1 \\
\hline Oranges, grapefruit & 1 \\
\hline Other candy bars (Milky Way, Snickers) & 4 \\
\hline Other candy bars, e.g., Milky Way, Snickers & 4 \\
\hline Other candy without chocolate (Skittles) & 4 \\
\hline $\begin{array}{l}\text { Other carbonated, low-cal beverage without } \\
\text { caffeine, (e.g., Diet 7-Up) }\end{array}$ & 4 \\
\hline Other cooked breakfast cereal & 1 \\
\hline Other fish, e.g., cod, haddock, halibut & 1 \\
\hline Other grains, like kasha, couscous, bulgur & 1 \\
\hline Other hot breakfast cereal, like farina or grits & 1 \\
\hline Other nuts & 1 \\
\hline $\begin{array}{l}\text { Other regular carbonated beverage with sugar (e. } \\
\text { g., 7-Up) }\end{array}$ & 4 \\
\hline Pancakes or waffles & $1^{\mathrm{a}}$ \\
\hline Pancakes or waffles or French toast & $1^{\mathrm{a}}$ \\
\hline $\begin{array}{l}\text { Pasta (e.g., spaghetti with sauce, lasagne): } \\
\text { chicken or turkey }\end{array}$ & 1 \\
\hline $\begin{array}{l}\text { Pasta (e.g., spaghetti with sauce, lasagne): } \\
\text { vegetable }\end{array}$ & 1 \\
\hline $\begin{array}{l}\text { Pasta (e.g., spaghetti with sauce, lasagne): beef/ } \\
\text { hamburger/pork }\end{array}$ & 1 \\
\hline Pasta (e.g., spaghetti with sauce, lasagne): plain & 1 \\
\hline Peaches, plums, apricots & 1 \\
\hline Peaches, plums, apricots (fresh, canned or dried) & 1 \\
\hline $\begin{array}{l}\text { Peanut butter sandwich (plain or with jelly, fluff, } \\
\text { etc.) }\end{array}$ & 4 \\
\hline Peanut butter, plain exclude sandwiches & 1 \\
\hline Peanuts & 3 \\
\hline Peanuts, nut & 3 \\
\hline Pears & 1 \\
\hline Peas or lima beans & 1 \\
\hline Peas or lima beans or soup & 1 \\
\hline Pie & $1^{\mathrm{a}}$ \\
\hline Pizza & 4 \\
\hline Popcorn & $3^{\mathrm{a}}$ \\
\hline Popsicles & 4 \\
\hline Poptarts & 4 \\
\hline Pork, ribs or ham as main dish & 1 \\
\hline Posicles & 4 \\
\hline Potato chips & $3^{a}$ \\
\hline Potato salad & 1 \\
\hline Potato salad & 1 \\
\hline Potatoes - baked, boiled, mashed & 1 \\
\hline Potatoes - baked or boiled, mashed & 1 \\
\hline Pretzels & 3 \\
\hline Pudding & $1^{\mathrm{a}}$ \\
\hline Pudding - EXCLUDE sugar free & 4 \\
\hline Raisins & 1 \\
\hline $\begin{array}{l}\text { Regular carbonated beverage with caffeine \& } \\
\text { sugar, (e.g., Coke, Pepsi, Mt. Dew, Dr. Pepper) }\end{array}$ & 4 \\
\hline
\end{tabular}


Table 4. Continued

\begin{tabular}{|c|c|}
\hline Food item & $\begin{array}{l}\text { NOVA group } \\
\text { assignment }\end{array}$ \\
\hline Regular hot tea with caffeine, including green tea & 1 \\
\hline Regular potato chips, corn chips, Doritos & $3^{a}$ \\
\hline Rice & 1 \\
\hline Roast beef or ham sandwich & $1^{\mathrm{a}}$ \\
\hline Safflower oil & 2 \\
\hline Salad dressing (not low energy) & 1 \\
\hline Salad dressing (not low energy) & 1 \\
\hline Salami, bologna or other deli meat sandwich & 4 \\
\hline Salsa & 1 \\
\hline Salsa & 1 \\
\hline Sandwich or wrap: beef & $1^{\mathrm{a}}$ \\
\hline Sandwich or wrap: chicken or turkey & $1^{\mathrm{a}}$ \\
\hline Sandwich or wrap: peanut butter \& jelly/fluff & 4 \\
\hline $\begin{array}{l}\text { Sandwich or wrap: salami, bologna or other deli } \\
\text { meat }\end{array}$ & 4 \\
\hline Sandwich or wrap: tuna & $1^{\mathrm{a}}$ \\
\hline Sandwich or wrap: veggie (no meat) & $1^{\mathrm{a}}$ \\
\hline Sausage & 4 \\
\hline Seeds (Sunflower or Pumpkin) & 1 \\
\hline Seeds, e.g., sunflower or pumpkin & 1 \\
\hline Shrimp, lobster or scallops as a main dish & 1 \\
\hline Shrimp, lobster, scallops & 1 \\
\hline Skim/non-fat milk & 1 \\
\hline Skim/non-fat milk (glass or with cereak) & 1 \\
\hline $\begin{array}{l}\text { Smoothies (e.g., medium Jamba Juice or Orange } \\
\text { Julius) }\end{array}$ & 1 \\
\hline Snack cakes, like Ring Dings/Swiss Rolls/Twinkies & 4 \\
\hline Snack cakes, like Twinkies & 4 \\
\hline Soda - not diet & 4 \\
\hline Soda - not diet & 4 \\
\hline Soya milk (glass or with cereal) & 4 \\
\hline Soya milk, any flavour & 4 \\
\hline Soyabean oil & 2 \\
\hline Spaghetti or other pasta with tomato sauce & 1 \\
\hline Spaghetti with tomato sauce & 1 \\
\hline Spinach & 1 \\
\hline Spinach, raw as in salad & 1 \\
\hline Sport drinks - Powerade or Gatorade & 4 \\
\hline $\begin{array}{l}\text { Spreadable butter (butter mixed with oil to make it } \\
\text { soft and spreadable) }\end{array}$ & 4 \\
\hline Strawberries & 1 \\
\hline String beans & 1 \\
\hline String beans & 1 \\
\hline Tacos/burritos/enchiladas & 4 \\
\hline Tacos/burritos/enchiladas - Beans & 4 \\
\hline Tacos/burritos/enchiladas - Beef & 4 \\
\hline Tacos/burritos/enchiladas - Beef and Beans & 4 \\
\hline Tacos/burritos/enchiladas - Chicken & 4 \\
\hline Tea-hot or iced & $1^{\mathrm{a}}$ \\
\hline Tofu & 3 \\
\hline $\begin{array}{l}\text { Tofu, soyaburgers, miso, edamame or other soya } \\
\text { dish }\end{array}$ & 4 \\
\hline Tofu/soyaburgers/other meat substitute & 4 \\
\hline Tomato juice or V8 & 1 \\
\hline Tomato sauce, e.g., spaghetti sauce & $3^{a}$ \\
\hline Tomatoes & 1 \\
\hline Tomatoes & 1 \\
\hline Tomatoes/tomato juice & 1 \\
\hline Tortilla - no filling & 3 \\
\hline Tortilla, e.g., tacos, quesadillas (exclude burritos) & 3 \\
\hline Tuna sandwich & $3^{\mathrm{a}}$ \\
\hline Vegetable oil & 2 \\
\hline Veggieburger & 4 \\
\hline Walnuts & 1 \\
\hline Water - tapped or bottled & 1 \\
\hline Watermelon & 1 \\
\hline
\end{tabular}

Table 4. Continued

\begin{tabular}{ll}
\hline Food item & $\begin{array}{l}\text { NOVA group } \\
\text { assignment }\end{array}$ \\
\hline Wheat or dark bread & 4 \\
Whipped cream & 4 \\
Whipped cream - EXCLUDE coffee drinks and/or & 2 \\
$\quad$ fat free & 4 \\
White bread, pita bread or toast & 4 \\
White or pita bread, exclude sandwiches & 1 \\
White rice & 1 \\
Whole milk & 1 \\
Whole milk (glass or with cereal) & 4 \\
Whole wheat or whole grain bread, include toast & 4 \\
Whole wheat or whole grain, exclude sandwiches & 4 \\
Wine or wine cooler & 1 \\
Yams/sweet potatoes & 1 \\
Yams/sweet potatoes & 4 \\
Yogurt - not frozen & 1 \\
Yogurt - plain, not frozen & 4 \\
Yogurt - artificially sweetened (e.g., light peach) & 4 \\
Yogurt - sweetened (e.g., strawberry, vanilla) & 1 \\
Zucchini, summer squash, eggplant &
\end{tabular}

Items will not add up to 315 - only one of two or more near-identical items (e.g., Corn chips/Doritos; Corn chips or Doritos) have been presented here.

${ }^{a}$ Indicates foods to be categorised as ultra-processed (4) for sensitivity analysis.

needs and applied to other studies. This work may also be valuable as a template for authors thinking about documenting and making transparent their method of classification to help increase the reproducibility of their research.

\section{Strengths and limitations}

The limitations of this approach are important to highlight. First, the present approach to classification assumed no changes to the food composition of the food item over time. As a result, the nutrient database from 2014 was used to determine the nutrient composition for all products irrespective of whether that product was listed in the FFQ in 1986 (first FFQ cycle in these cohorts) or in 2015 (the latest available FFQ cycle in these cohorts). The use of the nutrient database from 2014 likely confers a healthier nutrient composition to products that have been subject to reformulation ${ }^{(24,25)}$. Second, changes to the grade of processing over time because reformulation of the products was not captured by the present approach. Thus, the classification of a food product as ultraprocessed remained static over time. While it is likely that a small portion of foods switched between NOVA groups over the course of dietary data collection due to reformulation, future work would be needed to capture the evolution of the processing of these products.

A third limitation is related to the use of supermarket scans in informing categorisation. The asynchrony between the collection of the dietary information from participants and the website searches may result in the identification of different brands of products from the ones consumed by the participants and/or different levels of processing as gauged from the ingredient lists. In the present approach, ingredient lists of the most popular brands of products from 2019 to 2020 were used to reflect the processing of certain food items listed in FFQs from 1986 to 2015. To minimise the potential for 
misclassification, cohort-specific resources were given priority in informing the NOVA categorisation of most food items and the grocery website scans, while helpful, were only used to categorise a handful of products.

Finally, the food lists included a few food items that combined individual foods from different NOVA groups. While it is likely that the energetic contribution of each food was small, the approach to categorisation did not attempt to disaggregate the grouped foods to estimate the dietary contribution of each of the individual items. Single food items that were composite dishes (like baked dishes requiring multiple ingredients, some of which may be ultra-processed) were also not disaggregated into individual components, but instead, the dish in its entirety was categorised into a NOVA group.

The strengths of this approach were the triangulation of NOVA group assignment, expert review of the categorisation process, the use of supporting documents to inform the categorisation of the more challenging food items and the high transferability of the approach to categorising dietary data collected using other diet assessment methods in different contexts. The actual consumption levels as reported by the participants or participant demographics were not considered, so inherent systematic biases associated with the over- under-reporting of certain foods did not influence the categorisation strategy adopted.

\section{Conclusions}

This manuscript presents the strategy used in the identification of the ultra-processed portion of the food lists of FFQs in large-scale population studies. The iterative, conservative approach adopted, relied on discussions with experts and was informed by insights from the research dieticians, information provided by cohort-specific documents and scans of online grocery stores. All food items were assigned a primary NOVA group with some foods being ear-marked for further sensitivity analysis. Future work would be needed to certify the validity of this approach by comparing participant ultra-processed food consumption estimated through FFQs against diet records while using the present approach of dietary categorisation. An evaluation of the generalisability and feasibility of applying this approach to other study populations and contexts is also warranted. Documentation and discussions of alternative approaches for categorisation and the evolution of dietary assessment methods to better capture ultra-processed foods are encouraged.

\section{Acknowledgements}

N. K., S. R., E. M. S., J.-P. D.-C., M. D. made substantial contributions to the classification of the diet. L. S., F. F. Z., Q. S., T. T. F., C. M., W. W. provided expert input into the classification of the diet. N. K. led the development of the manuscript. S. R., E. M. S., J.-P. D.-C., M. D., L. S., F. F. Z., Q. S., T. T. F., C. M., W. W. gave critical feedback on the manuscript. All authors have read and approved the final manuscript.

N. K. was supported by a FAPESP fellowship (2019/22278-7). E. M. S was supported by a FAPESP fellowship (2018/17972-9).
The authors have no financial or non-financial competing interests to declare.

\section{Ethics approval}

This study uses secondary data and is exempt from ethics approval.

\section{Availability of data and material}

The datasets used and/or analyzed during the current study are available from the corresponding author on reasonable request.

\section{References}

1. Monteiro CA, Cannon G, Levy RB, et al. (2019) Ultra-processed foods: what they are and how to identify them. Public Health Nutr 22, 936-941

2. Lane MM, Davis JA, Beattie S, et al. (2020) Ultraprocessed food and chronic noncommunicable diseases: a systematic review and meta-analysis of 43 observational studies. Obes Rev 22, 13146

3. Chen X, Zhang Z, Yang H, et al. (2020) Consumption of ultraprocessed foods and health outcomes: a systematic review of epidemiological studies. Nutr J 19, 1-10.

4. Pagliai G, Dinu M, Madarena MP, et al. (2020) Consumption of ultra-processed foods and health status: a systematic review and meta-analysis. Br J Nutr 3, 1-11.

5. Costa CDS, Assunção MCF, Loret de Mola C, et al. (2020) Role of ultra-processed food in fat mass index between 6 and 11 years of age: a cohort study. Int J Epi 50, 256.

6. Monge A, Canella DS, López-Olmedo N, et al. (2020) Ultra-processed beverages and processed meats increase the incidence of hypertension in Mexican women. Br J Nutr 126, 1-28.

7. Mendonça RDD, Pimenta AM, Gea A, et al. (2016) Ultraprocessed food consumption and risk of overweight and obesity: the University of Navarra Follow-Up (SUN) cohort study. Am J Clin Nutr 104, 1433-1440.

8. Cunha DB, da Costa THM, da Veiga GV, et al. (2018) Ultra-processed food consumption and adiposity trajectories in a Brazilian cohort of adolescents: ELANA study. Nutr Diabet 8, 1-9.

9. Silva FM, Giatti L, de Figueiredo RC, et al. (2018) Consumption of ultra-processed food and obesity: cross sectional results from the Brazilian Longitudinal Study of Adult Health (ELSA-Brasil) cohort (2008-2010). Public Health Nutr 21, 2271-2279.

10. Willett W (2012) Nutritional Epidemiology. New York: Oxford University Press.

11. Hu FB, Satija A, Rimm EB, et al. (2016) Diet assessment methods in the Nurses' Health Studies and contribution to evidence-based nutritional policies and guidelines. Am J Public Health 106, $1567-$ 1572.

12. Martin-Moreno JM, Willett WC, Gorgojo L, et al. (1994) Dietary fat, olive oil intake and breast cancer risk. Int J Cancer 58, 774-780.

13. Subar AF, Thompson FE, Kipnis, et al. (2001) Comparative validation of the Block, Willett, and National Cancer Institute food frequency questionnaires: The Eating at America's Table Study. Am J Epi 154, 1089-1099.

14. Hernández-Avila M, Romieu I, Parra S, et al. (1998) Validity and reproducibility of a food frequency questionnaire to assess dietary intake of women living in Mexico City. Salud Publica de Mex 40, 133-140.

15. Bao Y, Bertoia ML, Lenart EB, et al. (2016) Origin, methods, and evolution of the three Nurses' Health Studies. Am J Public Health 106, 1573-1581.

16. Rimm EB, Giovannucci EL, Stampfer MJ, et al. (1992) Reproducibility and validity of an expanded self-administered semiquantitative food frequency questionnaire among male health professionals. Am J Epi 135, 1114-1126. 
17. Rockett HR, Wolf AM \& Colditz GA (1995) Development and reproducibility of a food frequency questionnaire to assess diets of older children and adolescents. J Am Diet Ass 95, 336-340.

18. Rockett HR, Breitenbach M, Frazier AL, et al. (1997) Validation of a youth/adolescent food frequency questionnaire. Prev Med 26, 808-816.

19. Willett WC, Sampson L, et al. (1985) Reproducibility and validity of a semiquantitative food frequency questionnaire. Am J Epi $122,51-65$.

20. Srour B, Fezeu LK, Kesse-Guyot E, et al. (2019) Ultra-processed food intake and risk of cardiovascular disease: prospective cohort study (NutriNet-Santé). Br Med J 365, 1451.

21. Romieu X, Khandpur N, Katsikari A, et al. Consumption of industrial processed foods and risk of premenopausal breast cancer among Latin American women: the PRECAMA study. Under review at Cancer Causes and Control.

22. Food and Agriculture Organization of the United Nations. (2015) Guidelines on the Collection of Information on Food Processing Through Food Consumption Surveys. Rome: FAO.

23. Willett WC (1994) Future directions in the development of foodfrequency questionnaires. Am J Clin Nutr 59, 171S-174S.

24. Van Camp D, Hooker NH \& Lin CTJ (2012) Changes in fat contents of US snack foods in response to mandatory trans fat labelling. Public Health Nutr 15, 1130-1137.

25. Spiteri M \& Soler LG (2018) Food reformulation and nutritional quality of food consumption: an analysis based on households panel data in France. Eur J Clin Nutr 72, 228-235. 